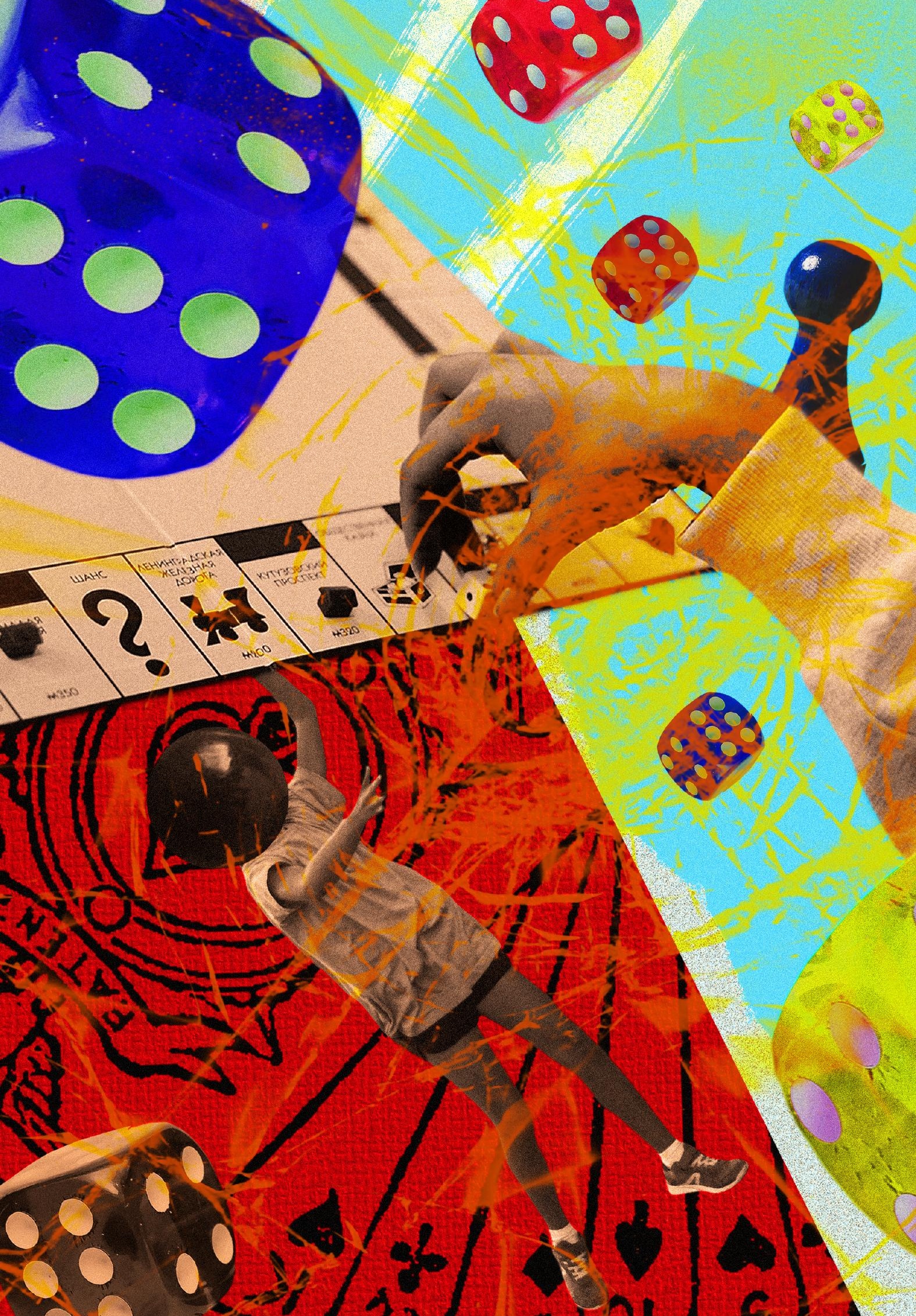




\section{O uso do jogo de tabuleiro humano na prevenção de acidentes domésticos na infância: relato de experiência}

Use of ludic to prevent domestic accidents in childhood: experience report

Lorena Gomes de Araújo Universidade Federal do Pará

Graduanda

lornena.lga1999@gmail.com

Edficher Margotti

Universidade Federal do Pará

Docente

edficher@ufpa.br

Amanda Gabrielly Miguel Rocha

Universidade Federal do Pará

Graduanda

amandagabmiro@gmail.com

Melissa Barbosa Martins

Universidade Federal do Pará

Graduanda

melissabarbosamartins@gmail.com

Gilcynara Maria Moura Rodrigues

Universidade Federal do Pará

Graduanda

mouranaah05@gmail.com

Natalia Tifanny da Conceição Universidade Federal do Pará

Graduanda

nataliatifanny98@gmail.com

\section{RESUMO}

O presente trabalho tem como objetivo relatar a experiência vivenciada por acadêmicas de enfermagem - integrantes do projeto de extensão "Acidentes domésticos na infância não é brincadeira", da Universidade Federal do Pará (UFPA) - na realização da atividade lúdica "Tabuleiro Humano", sobre a prevenção de acidentes domésticos na infância. Foi utilizada uma metodologia lúdica de ensino, em forma de tabuleiro, utilizando os próprios participantes como peças vivas do tabuleiro. A atividade foi realizada em dezembro de 2019, na classe hospitalar anexa ao setor de internação pediátrica de um hospital universitário de Belém-PA. O público-alvo foram crianças internadas na ala pediátrica, com seus respectivos acompanhantes. Compreende-se que as ações desenvolvidas com o uso de tecnologias educativas lúdicas foram de extrema relevância para promover a educação em saúde, principalmente quando se trata do atendimento ao público infantil.

Palavras-chave: Acidentes domésticos, Prevenção de acidentes, Enfermagem pediátrica, Criança, Jogos e brinquedos.

\section{ABSTRACT}

It aims to report the experience lived by nursing students, in carrying out the lucid activity "Tabuleiro Humano", on the prevention of domestic accidents in childhood. It is an experience report, about the experience of nursing students, members of the extension project "Domestic accidents in childhood is no joke", from the Federal University of Pará (UFPA). A lucid teaching methodology was used in the form of a board game, using the participants themselves as living pieces of the board. The activity was carried out in december 2019, in the hospital class attached to the pediatric inpatient sector of a university hospital in Belem-PA. The target audience was children admitted to the pediatric ward and also their parents, guardians, caregivers and / or companions. It is understood that the actions developed with the use of educational ludic technologies were extremely relevant for health education, especially when it comes to serving children.

Keywords: Accidents, Home accident Prevention, Pediatric nursing, Child, Play and Playthings. 


\section{INTRODUÇÃO}

Lesões não intencionais ou acidentes caracterizaram-se por episódios inesperados e indesejáveis, passiveis de ocorrer em diferentes ambientes, como na residência, na escola e na rua. Essas podem trazer, como consequência, danos físicos e/ou emocionais (Ferreira et al., 2014). As lesões podem ser: térmica, química, elétrica e/ou mecânica (Rede Nacional Primeira Infância, 2014).

Os acidentes domésticos ocorridos na infância, cada vez mais, representam graves problemas de saúde pública no Brasil (Vieira et al., 2019). Os acidentes decorrentes de envenenamento, trânsito, afogamento, queimaduras, quedas, entre outros, atualmente estão classificados como a principal causa da morte de crianças de 1 a 14 anos de idade (Secretaria de Vigilância em Saúde, 2020; Criança Segura, 2020). Esse cenário se repete em todo o mundo, não se alterando em paises considerados desenvolvidos ou não. Os acidentes domésticos se encontram entre as cinco principais causas de mortalidade (Fontinele, 2018).

Segundo dados do Ministério da Saúde, em 2017, a mortalidade por acidentes totalizou 3.661 casos - a maior parcela está na faixa etária de 1 a 4 anos. Quando comparado com os dados de 2007, o número vem decaindo; 5.106 casos. Apesar da queda no número de incidências de mortes por acidentes, os dados atuais ainda são expressivos e alarmantes (Criança Segura, 2020).

Analisando os últimos 10 anos - tendo como referência o ano de 2008 -, os indices de hospitalizações por acidentes oscilou. Porém, desde seu ápice em 2010, com 127.302 registros, os índices vêm diminuindo. Em 2018, atingiu o patamar de 111.555 hospitalizações, sendo a faixa etária de 10 a 14 anos a que mais acumulou casos (Criança Segura, 2020).

Dentre os principais tipos de acidentes, os que mais levam à hospitalização são: queda; queimaduras; e os acidentes no trânsito (Criança Segura, 2020).

As crianças, em decorrência da sua fragilidade fisica e imaturidade, são as mais vulneráveis, pois não possuem discernimento para identificar situações de perigo às quais possam estar expostas. Suas habilidades motoras, cognitivas e sensoriais ainda estão em desenvolvimento. Conhecer as especificidades de cada etapa desse processo de desenvolvimento é fundamental para prever determinados acidentes (Rede Nacional Primeira Infância, 2014).

Além disso, as ocorrências de eventos não intencionais estão ligadas a fatores como: a infraestrutura precária do ambiente, a falta de informação, o baixo nivel de educação dos cuidadores, a pobreza, a maternidade precoce, as familias monoparentais, e as familias volumosas. Apesar disso, qualquer criança está suscetivel à ocorrência de acidentes (Rede Nacional Primeira Infância, 2014).

O domicilio é um local propício para essas ocorrências. Os espaços domiciliares e escolares devem ser adequados e adaptados para as crianças. 
Algumas medidas simples podem minimizar os riscos, tais como: alertar os pais, cuidadores e responsáveis para a supervisão ativa das crianças e a atenção total para a organização dos ambientes (Rede Nacional Primeira Infância, 2014; Fontinele, 2018).

O público infantil é suscetivel a uma grande variedade de condições de risco à saúde. Assim, a educação em saúde caracteriza-se como uma estratégia eficaz para minimizar problemas, condutas, atitudes, hábitos e comportamentos que põem em risco a saúde da criança (Martins et al., 2019).

As ações de prevenção em saúde são vantajosas econômica e assistencialmente, já que mobilizam e/ou conscientizam sobre diversos problemas de saúde da população, colaboram para a redução do número de morbidade, comorbidade e mortalidade (Piantino et al., 2016). A educação na infância reflete em mudanças que irão impactar por toda a vida do indivíduo. Quando a criança entende que mudanças simples podem diminuir sua exposição a situações de perigo, ela assume funções ativas no processo de prevenção e promoção à saúde (Martins et al., 2019).

Diante do exposto, surge a necessidade de serem desenvolvidas atividades lúdicas para crianças e para os responsáveis, direcionadas para prevenção de acidentes domésticos que envolvam crianças. Atividades que busquem minimizar o alarmante índice de hospitalizações do público infantil. O lúdico faz parte de todas as fases da vida, mas é na infância que obrigatoriamente se faz presente e necessário tanto para o crescimento quanto para o desenvolvimento da criança. Seu uso no processo de ensino-aprendizagem, por meio da utilização das brincadeiras, jogos, músicas, brinquedos, teatro, danças e histórias, favorece e torna a experiência mais dinâmica, acessivel e prazerosa para as crianças (Martins et al., 2019; Rodrigues et al., 2018). O brincar é uma necessidade na infância, ou seja, é inerente ao desenvolvimento físico, social, emocional e cognitivo da criança, facilita a comunicação, a expressão e incentiva a criatividade, contribui para a socialização e para a adaptação a ambientes e a pessoas (Ferreira et al., 2014).

Considerando o exposto, surgiu a seguinte questão norteadora: como a aplicabilidade do lúdico impacta no processo de ensino-aprendizagem das crianças sobre a prevenção de acidentes domésticos? Deste modo, o presente texto tem por objetivo relatar a experiência vivenciada na realização da atividade lúdica sobre a prevenção de acidentes domésticos na infância: "Tabuleiro Humano".

\section{METODOLOGIA}

O projeto tem por finalidade o desenvolvimento de ações educativas e de conscientização com foco na redução de danos, medidas preventivas aos acidentes domésticos infantis, promoção e prevenção à saúde. 
No entanto, para se trabalhar a educação em saúde com o público pediátrico é necessário desenvolver ferramentas lúdicas e atrativas para transmitir o conteúdo de modo simples e de fácil entendimento. Partindo desse pressuposto, o grupo de acadêmicas, em reunião para a idealização da atividade, traçou a ideia de montar um jogo intitulado "Tabuleiro Humano" - visando aproximar as crianças do brincar.

O tabuleiro foi pouco extenso e montado com uma estrutura simples com o intuito de que todos pudessem jogar e que esse fosse mais dinâmico. O formato escolhido foi em trilha, cuja estrutura possui seis casas, linha de partida e chegada. Os participantes iniciam o jogo posicionados na linha de partida. 0 objetivo é vencer o jogo, chegando até o fim do tabuleiro.

As casas foram numeradas de 1 a 6 . Cada número tinha um comando, como: 1- Dance uma música de sua preferência; 2- Cante uma música da sua escolha; 3- Diga um exemplo de acidentes que podem ocorrer em casa; 4- O que é acidente doméstico?; 5- Fale dois tipos de acidentes domésticos que já aconteceram com você; e 6- Como evitar um acidente doméstico?

Foi utilizado um dado gigante, tipo clássico, um cubo de seis faces gravado com números de um a seis em cada lado.

Cada criança jogava o dado. O número que ficasse com a face voltada para cima indicava o comando a ser realizado pelas crianças.

\section{Figura 1}

Tabuleiro Humano elaborado pelas acadêmicas de enfermagem. Belém, 2019

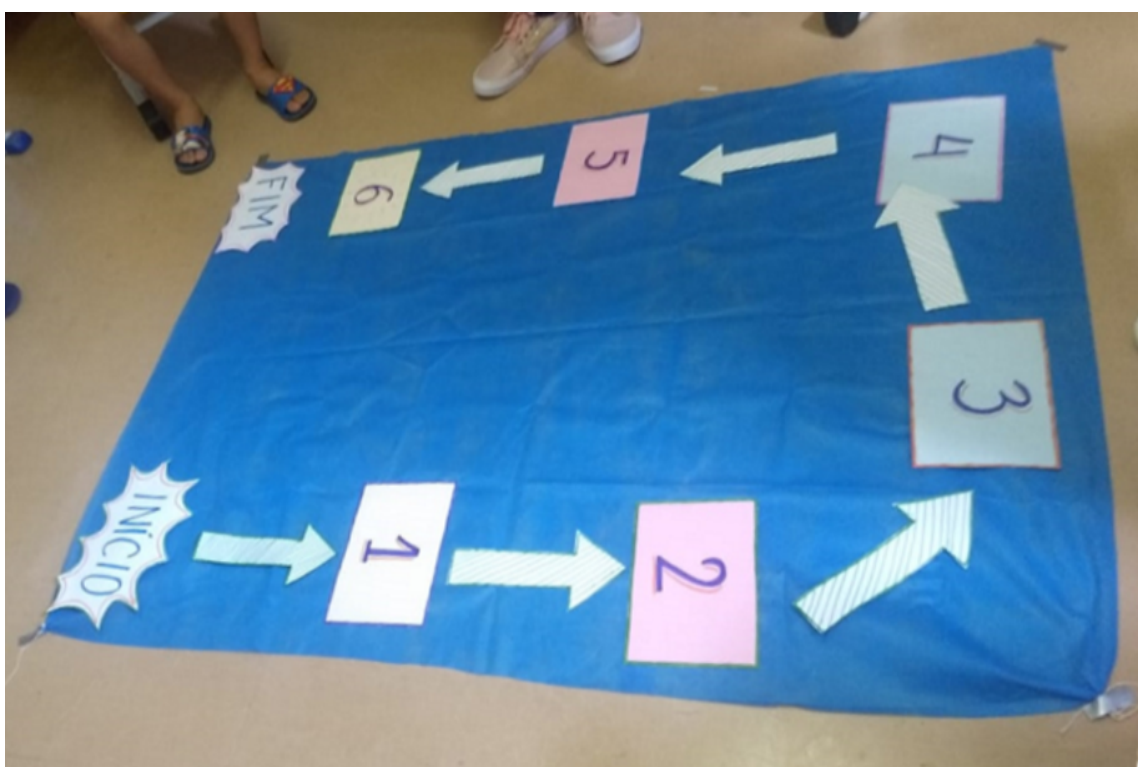

Fonte: Elaborado pelas autoras (2019). 
A atividade foi desenvolvida em dezembro de 2019, no periodo da manhã, na classe hospitalar anexa ao setor pediátrico de internação do hospital universitário João de Barros Barreto - Belém-PA. O público-alvo foram as crianças hospitalizadas na ala pediátrica e seus respectivos acompanhantes.

\section{RESULTADOS E DISCUSSÃO}

Ressalta-se que, antes da realização da atividade, a equipe passa pelos quartos para verificar quais crianças hospitalizadas que desejam e podem participar da atividade. Isso sempre respeitando a rotina hospitalar e a particularidade de cada criança no momento da atividade.

A dinâmica teve duração aproximada de 4 horas e contou com a participação de seis (6) crianças, sendo três (3) meninas e três (3) meninos, os quais se encontravam na faixa etária dos 4 aos 8 anos.

No início da ação educativa houve um momento destinado ao acolhimento, objetivando conhecer as crianças e suas histórias. Logo depois, foi feita uma contextualização acerca dos acidentes domésticos na infância a fim de avaliar a compreensão das crianças e dos acompanhantes acerca do assunto. Foram questionados sobre o que é acidente doméstico, suas causas, quais os tipos de acidentes e como preveni-los.

Após as explicações de como funcionaria o jogo, uma criança por vez jogou o dado e o número que ficasse para cima seria a casa que a criança deveria pisar no tabuleiro. De acordo com o número obtido, ela deveria realizar a ação especifica definida para cada casa do tabuleiro.

Figura 2

Descoberta do comando referente à casa pisada no Tabuleiro Humano. Belém, 2019

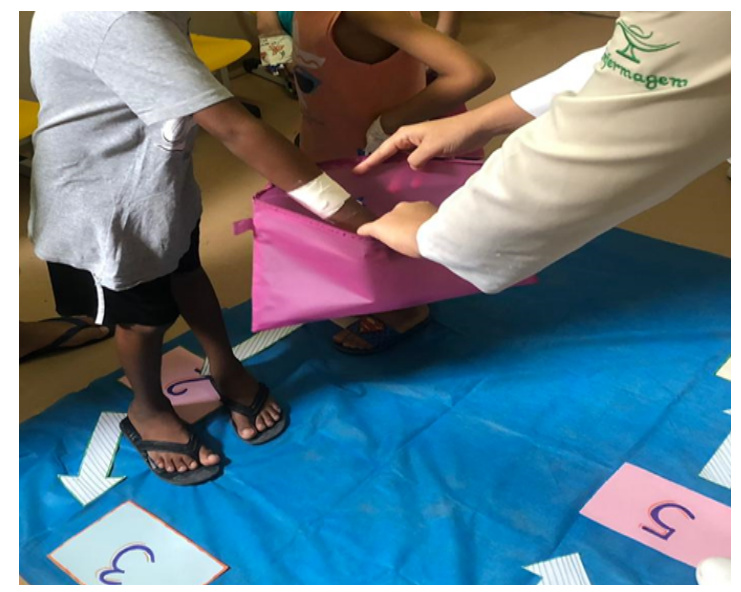

Fonte: Elaborado pelas autoras (2019). 
De início, as crianças apresentaram-se tímidas e pouco comunicativas com as acadêmicas. Destaca-se que, a princípio, ao comando de dançar e cantar, algumas demonstraram recusa em participar. Dessa forma, a equipe buscou incentivar a interação e a cooperação entre as próprias crianças. Então foi pedido para que dançassem e cantassem juntos, para que sentissem vontade de jogar, já que os jogos que buscam a cooperação e socialização tornam as crianças menos tímidas, pois, não as deixam em grande destaque perante as outras (Valente, 2014).

Ressalta-se que algumas crianças durante a dança apresentaram queixas de dor no corpo. Indagadas sobre o motivo, relataram que não costumavam se movimentar, pois passavam tempo excessivo paradas nos leitos das enfermarias do setor pediátrico.

Figura 3

Participação das crianças hospitalizadas na realização da dinâmica do Tabuleiro Humano. Belém, 2019

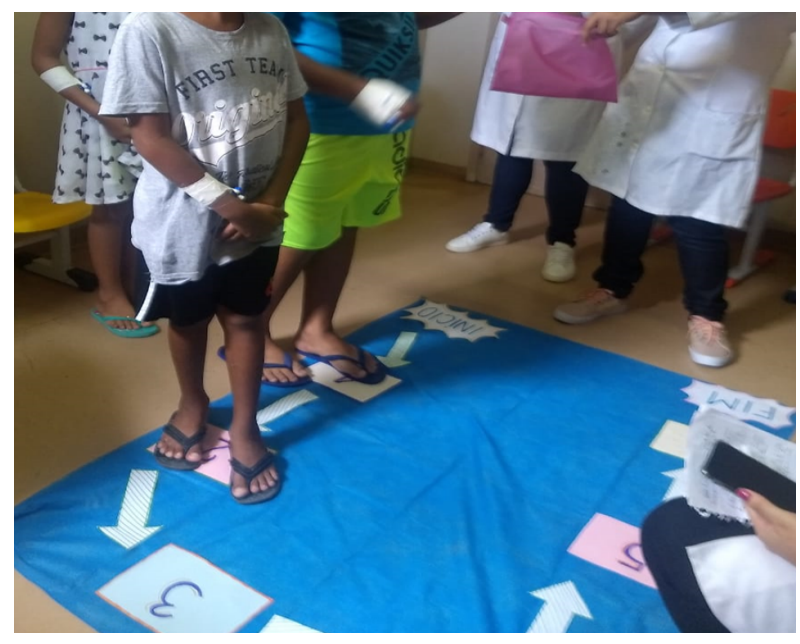

Fonte: Elaborado pelas autoras (2019)

No fim, o recurso de dançar e de cantar foram fundamentais para proporcionar um momento de descontração e de diversão, sendo perceptivel por risos, expressões faciais e corporais, além dos comentários positivos entre as crianças. Além disso, a movimentação do corpo contribuiu para o trabalho com a musculatura, para a coordenação motora, flexibilidade, postura e ritmo (Ribeiro, 2020).

Diante das perguntas relacionadas aos acidentes domésticos, após as respostas dadas pelas crianças, foi incentivada a troca de experiência entre os acompanhantes e as acadêmicas, a fim de romper a abordagem vertical da transmissão de conhecimento e criar uma consciência reflexiva para prevenção 
e promoção da saúde (Carvalho et al., 2018). Nesse momento, também foram realizadas intervenções sobre quais medidas e técnicas de primeiros socorros deveriam ser tomadas caso os acompanhantes presenciassem algum acidente doméstico. Foram demonstradas e explicadas algumas técnicas de primeiros socorros com intuito de diminuir a gravidade das lesões e manter a integridade da vida (Castro et al., 2019).

Quanto aos acidentes mais citados na conversa em grupo, entre os que ocorrem em domicilio, tiveram destaque os acidentes por queimadura e os por intoxicação pela ingestão de produtos químicos. Esses depoimentos vão ao encontro dos principais tipos de ocorrência de acidentes, no Brasil, que levam a emergências e, até mesmo, elevam a taxa de mortalidade (Azevedo et al, 2018).

Em suma, a utilização do lúdico proporcionou aos participantes um momento de reflexão e construção de conhecimento conjunto. A estratégia do tabuleiro humano se configurou como indispensável e eficiente para captar a atenção das crianças e buscar o entendimento por meio da brincadeira (Criança Segura Brasil, 2018).

O enfermeiro, tendo contato próximo com pacientes, assume o papel de educador e orientador no trabalho educacional de conscientizar e de sensibilizar a rede de cuidado à criança, e à população em geral, sobre como promover a prevenção de acidentes domésticos e de orientar sobre os primeiros socorros a serem prestados, a fim de garantir uma melhor qualidade de vida para as crianças (Passos, 2016).

Magalhães (2018) e Assis et al. (2019) afirmam que a enfermagem está diretamente ligada ao processo de educar, seja o indivíduo ou a comunidade. $\mathrm{E}$ pela educação é possivel modificar a forma de agir e pensar de uma sociedade, bem como fornecer benefícios para a melhoria da qualidade de vida.

Destaca-se que a experiência vivenciada ofertou às acadêmicas de enfermagem a oportunidade de agregar conhecimento e valores ao trabalharem a promoção e a prevenção em saúde com estratégias lúdicas de ensino, de forma a atenderem as necessidades do público infantil e auxiliarem em sua aprendizagem.

\section{CONCLUSÃO}

As ações educativas desenvolvidas com metodologias lúdicas são de extrema relevância para promover a educação em saúde, principalmente quando se trata do atendimento ao público infantil. Sua utilização corrobora para o despertar do interesse das crianças sobre o tema e também para a aquisição de uma postura que resulte em prevenção e promoção da saúde.

O projeto de extensão contribuiu positivamente para a obtenção de vivências únicas para as acadêmicas. Possibilitou trabalhar intimamente com o público pediátrico uma temática tão relevante para saúde pública, temática essa que necessita de esforços conjuntos para a conscientização em 
relação à prevenção de acidentes domésticos envolvendo crianças. Ademais, proporcionou a oportunidade de emergirem, na prática do serviço hospitalar, os conhecimentos teóricos aprendidos em sala de aula.

A enfermagem tem um papel fundamental na promoção e na proteção da vida. Ações sobre as quais, de acordo com a realidade da população, os profissionais devem pautar sua prática, favorecendo o processo de aprendizagem, principalmente no campo da saúde da criança, no qual se pode lançar mão do recurso lúdico. 


\section{REFERÊNCIAS}

Assis, B. A., Sousa, M. R. L., Eringer, P., Santos, R. R. P., Procópio, R. M., Sousa, R. F.; et al. (2019). O papel do enfermeiro como educador: relato de experiência vivida na aula prática de educação em saúde. Revista Uniltalo em pesquisa, 9(1),116-132. http://pesquisa.italo.br/index.php?journal=uniitalo\&page=article\&op=view\&path\%5B\%5D=265\&path\%5B\%5D=241.

Azevedo, A. P. F., Conceição, D., Oliveira, M. C. P., Aleknovic, M. A., Costa, Z. A., Abud, S. M. (2018). Perfil dos acidentes domésticos em crianças menores de seis anos. Univag Centro Universitário. http://www.repositoriodigital.univag.com.br/ index.php/enf/article/view/52/51\#.

Carvalho, K. M., Silva, C. R. D. T., Figueiredo, M. L. F.; Nogueira, L. T., Andrade, E. M. L. R. (2018). Intervenções educativas para promoção da saúde do idoso: revisão integrativa. Acta Paulista de Enfermagem, 31(4), 446-454. http://www.scielo.br/ scielo.php?script=sci_arttext\&pid=S0103-21002018000400446\&lng=en .

Castro, J. A., Cordeiro B. C., Andrade K. G. M. (2019). O conhecimento e a importância dos primeiros socorros para professores e funcionários em uma instituição de ensino federal do Rio de Janeiro. Debates em Educação, 11(25), 254-270. Disponivel em: http://200.17.114.107/index.php/debateseducacao/ article/view/7804.

Criança Segura. Conheça os dados sobre acidentes. https://criancasegura.org. br/dados-de-acidentes/.

Criança Segura Brasil. (2018). Como ensinar prevenção de acidentes às crianças. https://criancasegura.org.br/noticia/como-ensinar-prevencao-de-acidentes-as-criancas/.

Ferreira, N. A. S., Esmeraldo, J. D., Blake, M. T., Antão, J. Y. F. L., Raimundo, R. D., Abreu, L. C. (2014). Representação social do lúdico no hospital: o olhar da criança. Journal of Human Growth and Development, 24(2), 188-194. http://pepsic.bvsalud.org/pdf/rbcdh/v24n2/pt_11.pdf

Ferreira, T. N., Lima, J. N., Alencar, M. S.; Cangussu, P. C., Queiróz, S. E., Silva, A. G. Principais causas de acidentes domésticos com crianças menores de 5 anos de idade: uma revisão da literatura. (2014). EFDeportes.com . https://www. efdeportes.com/efd19o/causas-de-acidentes-domesticos-com-criancas.htm.

Fontinele, A. (2020). Os números dos acidentes domésticos no Brasil. Mãos dadas. 2018. http://ultimato.com.br/sites/maosdadas/2018/03/12/os-numeros-dos-acidentes-domesticos-no-brasil/. 
Magalhães, A. R. L. (2018). O papel do enfermeiro especialista na prevenção de acidentes escolares [Dissertação, Évora: Universidade de Évora]. http://dspace. uevora.pt/rdpc/handle/10174/23408.

Martins, V. H., Lima, K. M., Belfort, L. R. M., Santos, T. V. (2019). Brincando e aprendendo: a importância das ações em saúde voltadas para o público infantil. Revista de Extensão da UNIVASF, 7(1), 53-62. http://www.periodicos.univasf.edu. $\mathrm{br} / \mathrm{index}$.php/extramuros/article/view/934/682.

Passos, D. A., Santos, W. L. (2016). O enfermeiro como educador para a prevenção dos principais acidentes ocorridos na primeira infância. Revista de Divulgação Científica Sena Aires, 5(2), 124-135. http://revistafacesa.senaaires.com.br/index. $\mathrm{php} / \mathrm{revisa/article/view/264/137.}$

Piantino, C. B., Vanin, A. C., Vieira, M., Souza, D. H. I. (2016). Propostas de ações educativas no ambiente escolar como prática de promoção da saúde. Ciência et Praxis, 9(17), 49-52. http://revista.uemg.br/index.php/praxys/article/ view/2271.

Rede Nacional Primeira Infância. Mapeamento da ação finalistica evitando acidentes na primeira infância. http://primeirainfancia.org.br/ wp-content/uploads/2015/01/RELATORIO-DE-MAPEAMENTO-EVITANDO-ACIDENTES-versao-4-solteiras.pdf.

Ribeiro, I. Benefícios da dança para crianças. Portal da educação física. Secretaria da Educação do Paraná. http://www.educacaofisica.seed.pr.gov.br/ modules/noticias/article.php?storyid=169.

Rodrigues, I. R. S., Ribeiro, R. B. (2018). O uso do lúdico na Educação Infantil como facilitador do processo de ensino e aprendizagem. Revista Científic@ Universitas, 5(2), 20-26. http://revista.fepi.br/revista/index.php/revista/article/view/634/ pdf_35.

Secretaria de Vigilância em Saúde. Principais causas de morte. http://svs.aids. gov.br/dantps/centrais-de-conteudos/paineis-de-monitoramento/mortalidade/gbd-brasil/principais-causas/.

Soares, F. M., Gonçalves, A. B. C., Alvim, R. O., Júnior, C. A. M., Oliveira, C. M. (2017). Conscientização infantil: abordagem lúdica sobre utilização de recursos naturais. Revista Ciência em Extensão, 13(3), 87-92. https://ojs.unesp.br/index.php/ revista_proex/article/view/1454.

Valente, R. F. (2014). O jogo e a timidez em crianças em idade pré-escolar. [Tesis no publicada] Faro: Universidade do Algarve https://sapientia.ualg.pt/ bitstream/10400.1/8076/1/relat\%C3\%B3rio\%20dia\%2029setFINAL.pdf. 
Vieira, E. C. G., Souza, G. M. P. (2019). Prevalência de acidentes domésticos infantis no Brasil [Monografia, Distrito Federal: Centro Universitário do Planalto Central].

Data de submissão: 14/06/2020

Data de aceite: $22 / 12 / 2020$ 